\title{
A arte de advogar $(*)$
}

\author{
Waldemar Ferreira \\ Professor Eimérito da Faculdade de Direito \\ da Universidade de São Paulo.
}

I

\section{A linguagem forense e o estilo}

1. A virtude insigne do advogado como jurista, ademais dos atributos peculiares a todo homem bom, no aito sentido que esta expressão sempre teve, é a eloquência.

Revela-se a eloquência pelo talento, que muitos consideram ingênito, de bem falar, de persuadir e de convencer, que os antigos mestres de retórica mais simplesmente houveram como a arte de persuadir por meio do discurso. Nem faltou mesmo quem acrescentasse ser a faculdade, por tal meio, de mover os homens no sentido do juízo de quem o formula e exprime.

No âmbito forense mais se acentuou êsse caráter persuasivo da eloquência, assinalado com pompas de alviçaras, a que Quintiliano opôs restrições. A absolvição de Frinéia, tão decantada por muitas tubas, êle o disse, se verificou, não em consequência do discurso de HIPÉRIdes, ainda que admirável, mas à vista de seu corpo, que sendo formosissimo, ela teve o cuidado de descobrir, abrindo a túnica.

(*) Relatório do Tema II. ${ }^{\circ}$ da II. ${ }^{a}$ Comissão da Primeira Conferência Nacional da Ordem dos Advogados do Brasil, realizada no Rio de Janeiro em agôsto de 1958. 
Se irresistível, como poder de persuasão, se mostrou - estratagema, parece que a iniciativa do gesto, incrível e glorioso, não foi da acusada, mas de seu patrono, qual o poeta das Sarças de Fogo denunciou:

"Vacila o Tribunal, ouvindo a voz que o doma... Mas, de pronto, entre a turba Hipérides assoma, Defende-lhe a inocência, exclama, exora, pede, Suplica, ordena, exige.. O Areópago não cede. "Pois condenai-a agora!" $E$ à ré, que treme, a branca 'Túnica despedaça, e o véu, que a cobre, arranca"

de modo a que ela aparecesse, "diante da multidão, atônita e surpresa, no triunfo imortal da Carne e da Beleza"!

Referindo-se ao fato histórico, concluiu Quintiliano que êle abalava a definição da eloquência como a arte de persuadir pelo discurso.

Nem só a palavra tem o dom da persuasão.

Na humildade, na penitência, na castidade, na pobreza e na paciência, encontrou o poeta magno da língua

"Argumentos que às Musas põe espanto,

"Que faz muda a grandíloqua eloquência.

Podem fatôres inúmeros e imprevistos atuar sôbre o juízo humano, que nem sempre se forma no cérebro espontâneamente, senão por efeito dos mais díspares impactos sôbre as cordas emotivas dos sentimentos, gerando a persuasão. Mas não é êsse o meio correntio de a alcançar. O mais poderoso e fecundo ainda é a eloquência em ação direta sôbre a vontade, por via do discurso.

2. O discurso é operação mental por que, atuando sôbre a atenção do julgador pela palavra falada ou escrita, se busca levá-lo a formar juízo coincidente com o que lhe é transmitido ou inspirado. 
Não por outro motivo divisou LeIBNITz no discurso, processo tendente a fazer transitar o espírito de um para outro juízo, na sequência de certa ordem -- a da consequência; ou qualquer outra, como a do método. Discursus est transitus cogitantis a sententia ad sententiam ordine quodam, sive consequentiarum, sive alios, ut in methodo.

Essa transição espiritual se opera pelo raciocínio ou argumentação, no encadeiamento regular e necessário de processo lógico, destinado a revelar a verdade. Êsse é seu objetivo. Há que separar, na confusão do falso e do verdadeiro, o joio do trigo; e essa separação se estabelece pelo discurso, em que o raciocínio se ajuste com a prova, por ef eito da evidência.

3. É pelo discurso que o advogado cumpre o fadário de seu alto ofício; e o discurso se profere ou se escreve, a fim de demandar ou de defender, desatando-se em cinco momentos distintos e sucessivos, quais o proêmio, a narração, a prova, a refutação e a peroração, não raro entrecortados pelas digressões impostas pelas circunstâncias e a natureza da causa.

Examinando com agudeza conceitual a composição da peça de eloquência, o Abade CoLIN a desdobrou em quatro instantes dignos de recordação.

É o primeiro o da meditação sôbre o assunto, de molde a apreendê-lo no todo e nas particularidades, distinguindo seus pontos fortes e fracos. Tratando-se de advogado, cabe-lhe conceber distintamente o âmago da questão, de molde a escolher, no ataque ou na defesa, o seu ponto crucial; e para conduzir as fôrças de seu espírito, evitando a fadiga, dividirá o assunto em partes, a fim de as examinar uma após outra e compará-las em conjunto, verificando se, da reunião dêsses elementos, resultará a decisão da controvérsia e o ganho da causa.

É o segundo o da escrita do meditado, com o lançamento dos pontos fundamentais do discurso, esquematizando-lhe o plano, ordem e divisão; anotando as provas e as respostas às objeções, sem muito ter em conta a exa- 
tidão do estilo e as graças da linguagem, para que a atenção escrupulosa destas não amorteça o calor da exposição.

É o terceiro o da fixação das primeiras idéias, afastando o inútil, suprindo as deficiências, firmando os princípios admitidos como constantes e assim reconhecidos; de modo que as consequências, dêles extraídas, sejam justas $\mathrm{e}$ as respostas às objeções convincentes, nada deixando a desejar.

É o quarto o do aperfeiçoamento e polimento da peça, tornando exato o que era duvidoso, preciso o que era vago, suave o que era rude, supresso o que era supérfluo, ainda que brilhante parecesse, tratando o trabalho, não com ternura de pai, que perdôa, mas com severidade de juiz, que condena. ${ }^{1}$

4. Teve sempre forma específica o discurso forense. Estabelecendo-se a relação processual pela postulação ou exposição das partes, assim para pedir, como para contradizer, instaurando a instância, tanto o libelo quanto a contestação deveriam, e ainda é vigente êsse estilo judicial, deduzir-se por artigos ou articulados, e as alegações finais sob a forma narrativa.

Os articulados, doutrinou João Mendes Júnior, "trazem vantagens fáceis de apreciar, não só nara a determinação do objeto do litígio, quer quanto ao fato, quer quanto ao direito, como para a facilidade do expediente da prova; mas o abuso dos advogados demonstrou que essas vantagens poderiam ser fraudadas, não só pelos interessados em tornar as causas mais intrincadas e difíceis do que realmente são, como por aquêles que, por inépcia e ignorância, articulam mais do que convém ou menos do que é necessário, sem lógica e sem critério jurídico algum, tão certo é o conhecido ditado: arrazôe quem quiser, articule quem souber" 2

(1) AвbÉ Colin, Traduction du Traité de l'Orateur de Ciceron, Paris, M.Dcc.xxxviI, Che\%. Bure l'Ainé, Preface, pág. 57.

(2) Jõ̃o Mendes de Almeida Júnior, Direito Judiciário Brasileiro, Livraria Freitas Bastos, Rio de Janeiro, 1954, pág. 463. 
Estabelecia por isso a lei processual de 1850 que as petições iniciais ou de proposição da ação, contestações, iéplicas, tréplicas, embargos, rєconvenções, oposições, poderiam ser articuladas, quando versassem sôbre diversas questões de direito ou fatos sôbre que devessem ser inquiridas testemunhas; e seriam claros, precisos e não contraditórios, não criminosos, nem difamatórios e nem meramente negativos. Versariam ademais sôbre matéria de fato e sôbre coisa certa, pertencente e conexa com a causa.

Dispondo dessarte, resumidamente, em que modo se fariam os artigos, matéria sôbre a qual derramadamente haviam se espraiado as Ordenações, no liv. III, tit. LIII, aquela velha lei adjetiva compendiou preceitos atinentes à linguagem forense, que não devem ser olvidados.

Não se manifestou a propósito o Código do Processo Civil. Mais não exigiu da petição inicial do que a indicação do "fato e os fundamentos jurídicos do pedido, expostos com clareza e precisão, de maneira que o réu possa preparar a defesa" Perdura no entanto a velha praxe da articulação, que aquêle código todavia exigiu para o recurso dos embargos a acórdãos, nos quais êles "serão reduzidos a artigos" Idênticamente, o Código de Processo Penal preceitua que se faça no libelo "a exposição, deduzida por artigos, do fato criminoso"

O predomínio do processo escrito dominante no Brasil, só ensejou grandes oradores judiciários criminais, mercê da oralidade do julgamento pelo juri. Não obstou isso a que grandes advogados se formassem e assás se notabilizassem pela precisão orgânica de seus articulados e muito mais pela riqueza expressional e jurídica de seus arrazoados, divulgados alguns pelas revistas jurídicas e outros, em maior número, pela impressão em pequenas brochuras que lhes deram larga divulgação.

Instituído, com o código de 1939, o sistema da oralidade no processo civil, nem por isso a oratória alcançou êxito. Muito contribuiu para isso, em primeiro lugar, a ausência de ambiente adequado: colocados ao redor duma 
mesa juiz, escrivão e advogados das partes, em sala mesquinha, nenhum debate é possível, principalmente quando, durante a audiência, como que estranho ao que nela se passa, enquanto se inquirem testemunhas o juiz se põe a despachar seu expediente ordinário. Em segundo lugar, como os juízes rarissimamente proferem a sentença na audiência de julgamento, os advogados preferiram apresentar memoriais escritos, à guisa de razões finais.

Não teve melhor sorte a sustentação oral perante as Câmaras dos Tribunais de Justiça, em que ainda impera o antigo sistema das tenções.

Feito o relatório da causa pelo desembargador a que se distribuiu, escreve êle, reservadamente, seu voto; e os autos se concluem aos revisores, que também escrevem os seus a fim de não perderem memória da causa, a julgar-se meses, senão anos depois de haverem lido os autos e formado seus juízos.

Por isso, a sustentação oral, na sessão de julgamento, sôbre ser rara, mui dificilmente logra modificar os votos escritos e lidos.

A oralidade processual existe mais na lei do que na realidade. orador.

O advogado brasileiro é escritor muito mais do que

Escritor, deve ser homem de letras?

5. Não, responde Domenico Giuriati: o homem deve ser o que é. Não tem necessidade o jurisconsulto de ser literato. Certamente, quando escreve, cumpre-lhe fazerse compreender; e quando fala, fazer-se ouvir; evidentemente não cometerá erros gramaticais e cuidará de aproveitar-se daquela sedução de forma "che $i$ piu schivi allettando, ha persuaso". 3

(3) Domenico Giuriati, Arte Forense, Turim, 1878, Rouxa e Favale, pág. 109. 
Sim, ponderou Cresson: "l'avocat est un homme de lettres". Êle não se afasta de seu gabinete publicando trabalhos literários e judiciários. ${ }^{4}$

Não é bem assim. Insta que o advogado seja homem de letras no exercício da profissão, articulando, arrazoando, minutando, contraminutando nos autos e principalmente orando no pretório.

Para o orador, considerou Cícero necessário ademais unir ao estudo da retórica o da filosofia. Querendo criar para si mesmo um sistema de eloquência, confessou ter arrancado seus princípios do fundo da filosofia em vez de os buscar nas fôrças da retórica.

De tal arte, acrescentou, a eloquência judiciária, desdenhosamente olhada pelos filósofos, se viu privada das luzes e dos grandes recursos que da filosofia poderia ter recebido; mas, sustentada pela seleção dos pensamentos, despertou a admiração do povo.

Diversamente não se entendeu em tôda a parte; e entre nós, até aos fins do século passado, se sobressaía, nos exames preparatórios para a matrícula nas Faculdades de Direito, a pretexto de preparar juristas e oradores, o de filosofia e retórica, substituídos, nos cursos ginasiais, pelo de lógica, ao depois suprimido.

Conjugam-se efetivamente a retórica e a lógica sem se confundirem; e não sem justeza observou SAINT-PRIX diferirem muitas vêzes essas duas artes pelos meios e também pelo fim. Não tem o lógico outra arma senão a verdade. O retórico, ou seja o orador, usa e abusa da comparação. O lógico quer convencer; mas o orador se contenta, não pouco, apenas com persuadir. ${ }^{5}$

6. Não se diga que a linguagem jurídica deve necessàriamente ser severa, abstrata, precisa e fria. Que assim

(4) M. Cresson, Usages et Règles de la Profession d'Avocat, Paris, 1888, L. Larose et Forcel, tomo II, pág. 11, n.o virI.

(5) F́́lix Berriat SAINT-Prix, Manuel de Logique Juridique, Paris, Librairie Plon, pág. 1, n. 2. 
se redijam os textos legislativos, compreende-se, mercê de seu tecnicismo.

Os textos legislativos devem ser simples, sem nenhuma subtileza, de molde a serem entendidos ainda pelos mais mediocres.

Não assim no entanto com o discurso forense, que é peça técnica, tramada lògicamente, para a demonstração da verdade de certa proposição destinada a provocar a sentença do juiz.

Não se deslustra, em qualquer de suas espécies, com a sóbria clareza da exposição em linguagem límpida, mas perfeita na forma, quanto elegante na frase e primorosa no estilo.

Existe a linguagem das leis, fixada pela tradição, diversa da linguagem comum; e o vocabulário jurídico nem sempre coincide com o ordinário, de uso vulgar. Palavras se deparam de sentido específico e próprio, que valem como moeda corrente, tanto que batidas.

Confere o tecnicismo jurídico a certas palavras, particular autoridade.

Disse-o Jean Ray.

Elas não são plenamente inteligíveis; e, por consequência, de uso entre os especialistas, ou sejam os iniciados. Os vocábulos que entram no texto da lei nela se impregnam, como se revestidos de caráter sagrado. Tomados de empréstimo à linguagem comum, como elementos do texto, adquirem ar de santidade, que é, para as sensibilidades individuais, o signo da autoridade social. ${ }^{6}$

Se o texto legislativo subsiste até centenàriamente, pelo menos em boa parte, como acontece com o do Código Comercial, a padecer sòmente a variedade de sua interpretação, de molde a conciliar-se com o tempo que passa, não se verifica o mesmo com a linguagem jurídica, como igualmente com a linguagem comum, de contínuo deturpada.

(6) JEAN RAY, Essai sur la Structure Logique du Code Civil Français, Paris, 1926, Librairie Félix Alican, pág. 37. 
Observou-o de há muito, magistrado francês.

A propriedade das palavras, sua exata conformidade com a idéia a exprimir deve distinguir o estilo judiciário. Pela utilização constante da palavra própria (proprius, particular) se obtém frase luminosa e a concisão que, em documento de justiça, é a qualidade primeira.

Empregar, ao contrário, a expressão geral pela precisa, o vocábulo de sentido deturpado pelo de significação direta, é produzir a obscuridade; ou, recorrendo aos epitetos e aos advérbios modificativos, estabelecer o embaraço e a difusão. ${ }^{7}$

Ora, quanto à impropriedade das palavras, é de salientar o que ocorre quanto ao "têrmo", tècnicamente o dia no qual tem de começar ou se extinguir a eficácia do negócio jurídico, substituído por "término"; e, quanto ao epíteto, o do Supremo Tribunal Federal, que, em seus próprios acórdãos, se intitula "Pretório Excelso", o que é desconcertante.

Recordando a definição de "processo" de Pereira E SouzA, qual a de ser a forma estabelecida pelas leis para se tratarem as causas em juízo, JoÃo Mendes JúNIOR escreveu ensinamento magistral.

"Mover", doutrinou, "mover nada mais é do que dar à matéria, nihil aliud est quam educere aliquid de potentia in actum, id est, de materia in formam, dizem os filósofos; por isso, os atos do processo nada mais são do que a forma da ação em Juízo. O ato, diz Aristóteles, é indefinível, porém devemos explicá-lo por proporção à potência. A primeira proporção é da forma para a matéria; a segunda proporção é do movimento para a potência motiva e da operação para a potência operativa (Metaphys., Ix, cap. viI). Comentando êste texto, diz Santo Tomaz que o nome ato é primeiramente atribuído à operação e assim todos entendem; mas depois é transferido à forma, enquanto a forma é princípio e fim da

(7) Pigrre Mimin, Le Style des Jugements, Paris. 1927, JurisClasseurs Éditions Godde, pág. 13. 
operação. Neste sentido, a definição de Pereira E Souza exprime perfeitamente a essência metafísica do processo judicial. As outras definições conhecidas são descritivas e, de entre essas, é excelente a adotada por Paula Batista: "o processo é o modo de fazer marchar a ação segundo as formas prescritas pelas leis".

"A definição subjetiva, porém, que, além disso, como diz Strikio, exprime a coisa in physicam essentiam, é aquela: o processo judicial é o movimento dos atos da ação em juízo...A definiçâo objetiva, que exprime a coisa pelo seu conteúdo, adotada pelos glosadores e pelos canonistas, é esta: o processo judicial é o complexo de atos $e$ termos da ação em Juízo" 8

Exprime o vocábulo "processo", até em sua essência física, o movimento dos atos judiciais; mas está a infiltrarse no vocabulário jurídico a nomenclatura "processamento", talvez porque os modernos homens do foro nutrem o propósito de imprimir maior celeridade ao "processo", servindo-se do sufixo "mento", formador dos substantivos que indicam ação, na generalidade dos casos.

Será? Exemplos outros poderiam ser trazidos à baila a fim de revelar como a linguagem jurídica, de tanta propriedade, sofre a ação do tempo, mercê dos descuidos dos que dela se servem imperitamente. Deformam-se os vocábulos; e o estilo forense, de precisão incomparável, ora míngua, ora se entumesce, perdendo não pouco de seu prestígio. Não acreditam os jovens juristas, na sua inquietude natural, que in antiquis est scientia.

Provocam com isso a reação dos mais antigos, que levou Timon, na primeira metade do século passado, a formular, dos advogados de então, e melhor é reproduzir suas palavras em sua língua original, para que não se descubra nenhuma alusão aos de agora, juízo que tem o defeito da generalização. "Aujourd'hui, nous ne rencon-

(8) JoÃo Mendes DE AlMeIdA JÚNIOR, Direito Judiciário Brasileiro, Rio de Janeiro, 1954, 4. a edição, Livraria Editora Freitas Bastos, pág. 201. 
trerions peut-être pas un seul avocat qui sût rédiger une consultation, dresser une thèse, argumenter par argumentation, faire un livre. Un avocat est un homme aimable, qui a de charmantes manières, qui mène à grands guides un élégant wiski, qui dompte un cheval fougueux, qui peigne ses moustaches, qui a bon feu, bonne compagnie, et qui joue à la bouillotte". ${ }^{9}$

Ora, hoje os advogados nem bigodes têm.

II

Os argumentos de autoridade e o eruditismo

7. Na defesa de sua tese não dispensa o advogado nenhum dos meios de a comprovar. Exposto o caso concreto, examina-o em face do texto legislativo que lhe serve de fundamento, assim do ponto de vista doutrinário, como pelo prisma do direito comparado. Recorre à jurisprudência à cata das disposições concernentes aos casos análogos. Não se contenta nunca com os seus próprios conhecimentos jurídicos, desconfiando de seus méritos. Eis porque ostenta erudição e entra a invocar os argumentos de autoridade.

Contra essa prática está a se esboçar forte corrente em prol da simplificação do discurso forense, de molde a reduzi-lo a meros articulados de extrema concisão, a bem dizer sumária, com o apenas necessário para a formação do juízo do julgador.

Seria isso realmente o ideal se os juízes fôssem de tal penetração de espírito e tão larga quão profunda cultura jurídica, que apreendessem a relação processual de golpe ou no ar. Pensaram assim os que militaram na campanha instituidora do chamado processo oral, no pressuposto de que os juizes, atentos à produção da prova, de

(9) Timon, Livre des Orateurs, $11 .^{\mathrm{a}}$ ed., Paris, 1842, Pagnerre, Editeur, pág. 119. 
posse dos elementos já passados pelo crivo de sua inteligência no momento da prolação do despacho saneador, ouvindo os debates verbais dos advogados, imediatamente se achariam iluminados para o ditado de sua sentença.

Julgar não é tão fácil como muitos supõem. O jôgo dialético das partes no pretório nada tem de parecido com o jôgo de pés sôbre bola de couro no campo de futebol. Se os fatos, que geram os conflitos de interêsses privados, nem sempre são simples, a complexidade do problema juridico é de maior monta e demanda exames e estudos, que exigem meditação e pesquisas científicas muitas vêzes.

Não impròpriamente doutrinou Sabatier que, para estar à vontade em ciência tão complexa, tão sutil, tão ondeante, como a ciência jurídica, sobretudo a ciência jurídica aplicada, não basta simplesmente razão sadia: é preciso razão maleável, misto de juízo sólido e raciocínio engenhoso, muita clareza de espírito para apreender as idéias gerais e o senso de minúcia a fim de descer ao âmago das idéias particulares com obediência firme aos princípios e cautela com as exceções. Ocorreu-lhe por isso, diante dum jurisconsulto, a lembrança de instrumento de rara precisão e infinita sensibilidade, com o qual se analisam e medem as ações humanas. ${ }^{10}$

8. Tem cada advogado método próprio de trabalho, em verdade personalíssimo. Se, na propositura da ação, imenso deve ser seu esfôrço para arquitetação de seu libelo, desde o estudo dos fatos, pois ex facto jus oritur, assentando com precisão o originador do direito e o ato de sua violação, até as alegações finais ou o discurso na audiência de instrução e julgamento - mui difícil se mostra fixar as regras do trabalho forense, diante das circunstâncias especialíssimas de cada caso concreto.

(10) Sabatier, Études et Discours, pág. 256, em FabreguetTes, A lógica judiciária e a arte de julgar, versão de Henrique de Carvalho, Rio de Janeiro, 1914, Jacinto Ribeiro dos Santos, Livreiro-editor, pág. 498. 
São inúmeras as regras fundamentais dêsse trabalho, aqui mesmo já delineadas, de resto. Expositor e argumentador, o advogado se dirige quase sempre à razão, muito mais que à emoção. As regras de gramática, de estilística, da lógica e de retórica são assás conhecidas, a despeito de que Renan houvesse dito alhures ter sido a retórica, com a poética, o único êrro dos gregos: não existe a arte de falar, tão pouco a de escrever.

Em que pese ao paradoxo elegantíssimo, não se absteve CícÉro de traçar as normas, cuidados e delicadezas da arte de escrever e de falar, que os advogados se esforçam por observar, cada um a seu modo; mas é de não perder de conta que o discurso forense se destaca sobretudo como peça lógica, destinada a convencer, e não a ensinar.

Mais é o advogado consciencioso, observou o bastonário Fernand Payen, pois estudou os autos, muito mais penoso lhe é ser claro e ordenado. De resto - porque os autos não escapam à lei comum e parecem de maior complexidade a cada exame - é de boa medida que o advogado, que o conhece bem, não se deslembre de que o juiz não o conhece do mesmo modo. Se o conhecesse, correria o advogado o risco de enfrentar opinião diferente da por êle já formada. E é mais difícil dissipar o êrro do que a ignorância. ${ }^{11}$

A ignorância é estado provisório de espírito, que se desvanece com explicação hábil e fluente do negócio jurídico, no fato em si, como no direito, que lhe seja aplicável. Mas o êrro é de correção assás trabalhosa, por efeito da própria contingência humana. Se ninguém se apraz com o cometer, nem por isso se agrada com o confessar; e o juiz é homem. Mais do que homem, é juiz; e tem o natural pecado de se supôr infalível; por isso, insuscetível de erronia.

(11) Fernand Payen, Le Barreau (L'Art et la Fonction), Paris, 1934, Éditions Bernard Grasset, pág. 245. 
Acresce que a instância judicial é contraditória; e a relação processual se desata entre a afirmação e a negativa.

A missão do advogado é a de argumentar. Argumenta, baseado no texto legal, generalizando-o ou especificando-lhe o sentido, de molde a ajustá-lo ao caso; argumenta, na omissão legislativa, invocando as disposições concernentes aos casos análogos do direito nacional, do mesmo modo que do direito estrangeiro; argumenta pelos demais processos lógicos; e argumenta sobretudo em face da jurisprudência e da doutrina, mercê de sua autoridade.

O advogado, doutrinou Rafael Bielsa, hoje mais que nunca, apoia sua argumentação, tese ou alegação, em fontes jurisprudenciais ou doutrinárias, o que é louvável, desde que as citações sejam verdadeiras, necessárias ou, ao menos, oportunas, bem individualizadas, precisas, ordenadas e, desde logo, de autoridade. A observância dessas condições, acresceu o jurisconsulto argentino, é índice de consciência e responsabilidade intelectual do advogado ou do jurista, que cita, tanto no científico (forma e técnica das citações), como no moral (autenticidade e fidelidade). ${ }^{12}$

$\mathrm{O}$ argumento de autoridade não tem sido desdenhado nem pelos maiores advogados.

Baste, para exemplo edificante, o de Rui Barbosa.

Jurista imenso e constitucionalista incomparável, orador do porte de Cícero, em todos os seus trabalhos empregou a argumentação de autoridade com frequência; mas com oportunidade.

Nem se furtou de pôr na balança o pêso das autoridades, em certo passo invocadas.

"Nem seria", arrazoou, "nem seria, me parece, com a magia de Planiol, quando mesmo o abalizado civilista militasse, aqui, entre os dissidentes. Porque Planiol é uma unidade insigne; mas não é uma legião, nem oráculo.

(12) Rafaer Bielsa, La Abogacia, Buenos Aires, 1945, Imprenta de la Universidad Nacional del Litoral, Santa Fé, pág. 262. 
Brilha nele o gênio, eminentemente francês, da precisão, do método e da clareza. O seu Tratado Elementar é o compêndio ideal. Ali o talento cristalino do autor reflete com admirável pureza, em facetas de uma limpidez sem jaça, análises e sinteses do lavor mais primoroso. Com todos êsses dotes, porém, de um raro didata, não é no saber e na autoridade, maior que os grandes nomes da literatura jurídica em seu país, ou na Bélgica e na Itália. A não ser, pois, que as razões de Planiol esmagassem as dos outros, entre unidades equivalentes, onde o maior número, aí a vantagem. Planiol seria um só contra muitíssimos outros; de modo que, ainda me falhando êle, o vencimento era meu, por maioria poderosíssima". ${ }^{13}$

$\mathrm{Na}$ generalidade dos casos recorre o advogado ao prestígio do argumento de autoridades, não tanto por desconfiar de sua própria autoridade, ou seja dos argumentos aduzidos, senão para se libertar da suspeita gerada pelo seu interêsse na apreciação da causa, perante o juiz.

De outro lado, tem sido considerável a influência exercida pelos advogados em bem do desenvolvimento do direito nacional. Casos novos, criados pela infiltração dos negócios internacionais, têm aparecido à barra dos tribunais, abrindo novos caminhos para a doutrina, trazida pelos argumentos de autoridades de aquém e de além mar; e seguidos naturalmente pela jurisprudência nacional.

9. Não incide em censura essa prática, antiquíssima de resto. Quem compulsa os velhos tratadistas, tanto os reinícolas, quanto os estrangeiros, verifica a imponência do argumento de autoridade. As citações são avultadas ao fim de cada período, quando não de entremeio ao próprio texto. E'a majestade dêsse sistema de argumentar não é peculiar aos advogados. Sentenças e acórdãos se deparam, nas revistas jurídicas e nos repertórios de juris-

(13) Ruy Barbosa, A Transação do Acre no Tratado de Petrópolis, Rio de Janeiro, 1906, Tip. do Jornal do Comércio de Rodrigues \& C., pág. 41. 
prudência, com os respectivos considerandos seguidos de citações em número avultado.

Não faz mal a ninguém a erudição dos juristas; e bem dosada, ela opera como condimento precioso, que empresta o sal, que tonifica, quando não o açucar, que deleita. Tem virtudes em verdade; mas não raro defeitos, principalmente quando os ensinamentos doutrinários se proferem em face de dispositivos ab-rogados ou a que se não ajustam convenientemente.

"Tudo", ensinou JoÃo Monteiro, "tudo tem o seu lugar e propriedade. Se a erudição incabida e indigesta é em regra prejudicial à causa e aos créditos profissionais do advogado, todo trabalho apropriadamente erudito haverá sempre de honrar o foro, e noventa sôbre cem vêzes dará vitória ao respectivo produtor. Se é escusada a supersticiosa observância do culto antigamente prestado às máximas de Quintillano e aos preceitos de HoRÁcıo, lembrados por LoBÃo àquela nota de Souza, furtemo-nos todavia de lhes fechar de todo os olhos, apavorados do receio de cançar ou tediar os juízes. Tanto pior para êles, se em tal desgraça se fotografar a magistratura do país. DEMostenes, o príncipe dos helenos advogados, iluminou o foro grego associando, em suas imortais orações, o flóreo despotismo da fantasia, no dizer de Latino Coelho, à realidade austera do mundo objetivo. Nem a currente rota, que estraga a causa, nem a êxtase literária, que anestesia o direito, em vez de o pôr em estado de energia defensiva. Em uma palavra: seja sempre erudito quem o souber corretamente ser; escreva tão pouco quanto possível, e, quanto menos, melhor, quem só desordenadamente souber se emaranhar nos difíceis meandros de erudição forense". ${ }^{14}$

10. É o argumento de autoridade de considerável prestância aos labores dos homens do foro.

(14) João MonteIro, Programa do Curso de Processo Civil, São Paulo, 1912, 3. ${ }^{\text {a }}$ edição Duprat \& Comp. vol. III, § 187, n. III, pág. 13, 
Depara-se nele o ensinamento de tratadistas a propósito de problemas doutrinários ou de interpretação dos textos legislativos, admitindo a existência ou revelando o conteúdo de regras de direito, aplicáveis a casos análogos; e desinteressadamente, do ângulo visual de cada um.

Reside nessa insuspeição a razão de sua grandeza; e não é incomum que se convole, por sua aceitação generalizada e observância contínua, em autêntico costume jurídico, por fôrça da opinio juris, que o sedimenta.

Não tem o argumento de autoridade caráter impositivo onde quer que se invoque; mas é de se acolher, se consoante com a razão e os princípios gerais de direito.

\section{III}

A comunicação dialética do advogado com o juiz

11. Atribuindo à corporação dos advogados esforçarse, quanto possível, para que, na escolha dos juízes, as considerações políticas não sobrepujem as aptidões judiciárias, propugnando no sentido de se aproveitarem para a magistratura juristas que tenham verdadeira vocação para êsse alto mister - o Código de Ética Profissional cuidou de colocar os magistrados na mais elevada posição, de molde a não se transviarem no justo critério e serena imparcialidade na apreciação dos assuntos submetidos ao seu julgamento.

Para êsse objetivo, vedou aos advogados o exercício de qualquer influência nas decisões dos juízes, com êles conversando em suas casas, nos auditórios de justiça; ou, onde quer que seja, escrevendo-lhes ou fazendo-lhes pedidos, diretamente ou por interposta pessoa; e lhes impôs o dever de os tratar com o maior respeito, discrição e independência, sem dispensar igual tratamento por parte dêles e sem olvidar que uns e outros colaboram na mesma obra e servem a mesma causa com igual dignidade e nobreza de ofício. 
12. O fim do direito, ou sua teleologia, é a justiça. Fazê-la reinar, observou Edmond Picard, é estabelecer, em suas mais perfeitas condições, as relações sociais que reclamam a proteção coativa da coletividade, ou do Estado. ${ }^{15}$ Pensamento foi êsse que assás se desenvolveu até se chegar à concepção do processo como instrumento da investigação da verdade e de distribuição da justiça, sob a autoridade do Estado.

Nunca se entendeu diversamente, em verdade se diga, porque se houvesse atribuído aos litigantes maior ou menor faculdade de iniciativa. A despeito de se ter muito falado e escrito, com a introdução do chamado processo oral, a propósito da autoridade conferida ao juiz para a determinação dos atos e têrmos mercê dos quais o processo se desata - a condução da lide é muito mais dos advogados, que do juiz: êste, hoje como ontem, toma conhecimento dela só por provocação das partes.

Era arcáico o processo antigo, murmurava-se: tornarase arma do litigante, meio de protelações de situações legítimas. Seus benefícios eram maiores para quem lesava o direito alheio do que para quem acorria em defesa do direito próprio. Atribuía-se êsse retardamento à ação dos advogados; e o meio de afastá-la era o de conferir ao Estado, assim na organização judiciária, quanto no processo, o dinamismo decorrente de sua atuação por via do magistrado.

Êste não tem porém a agilidade desejável, em razão de circunstâncias inúmeras: as audiências de instrução e julgamento se marcam para dias afastados, as sentenças se retardam e há desembargadores e ministros que levam semestres e até mais de ano para a feitura dos relatórios ou passagem dos autos que devem ler.

Não se desvanece, nem mesmo mercê dessa irremovível anomalia, a preocupação do advogado em precipitar a solução da lide, em que se ensejam momentos em que

(15) Edmond Picard, Le Droit Pur, Paris, 1908, Ernest Flammarion, Editeurs, $\S 170$, pág. 303. 
deve debater com o juiz incidentes processuais ou recorrer de suas decisões, nos casos e forma da lei.

13. O direito, no pensamento de Piero Calamandrei, até que não seja turbado ou molestado, é invisível e impalpável como o ar que se respira: é como a saúde, cujo preço sòmente depois de perdida se avalia. Ameaçado ou violado, o direito, descendo ao mundo dos sentidos do mundo astral em que pairava em regime de hipótese, se encarna no juiz e se converte em expressão concreta de vontade operante na sua palavra; e então "il giudice é il diritto fatto uomo" Eis porque, acrescentou o admirável escritor não há muito finado, se depara na iustitia, não simplesmente no ius, o verdadeiro fundamentum regnorum; e se o juiz não é justo, a voz do direito se elanguesce e se torna longínqua como a inaudível voz dos sonhos. ${ }^{16}$

Nem só o juiz personaliza o direito, senão igualmente o advogado, posto ao lado dêle a fim de o acompanhar, não como acólito, mas como defensor da lei, no tocante ao direito inidividual, pelo qual pleiteia; e, no tocante ao direito da coletividade, através do representante do Ministério Público.

No paralelismo dessas linhas de atividade judiciária, a faina do advogado é a de emitir a palavra que o juiz deve ouvir para julgar, em dialética serena e equilibrada em que a pessoa do julgador seja abstraída do seu julgado. Esste é impessoal: é despacho, é sentença, é acórdão. Como tal, é discutível, é criticável, é recorrível até que se convole na coisa julgada, que vale como lei e como tal se cumpre e se executa coativamente pelo poder do Estado.

Tendo achado que a conciliação em fórmula precisa dos direitos e os deveres dos advogados em relação aos magistrados é um pouco como a quadratura do círculo Fernand Payen observou todavia, que, na prática, milhares

(16) Piero Calamandrei, Elogio dei giudici scritto da un avvocato, Florênça, s/d, 2. ${ }^{\mathrm{a}}$ ed. Le Monnier, pág. II. 
de advogados todos os dias criticam os julgados sem criticar os magistrados que os proferem; exprimem-se, com tôda independência, sôbre as leis e os poderes estabelecidos sem nada dizer de atentatório daquelas e dêstes; protestam, com indignação, contra arbitrariedades, sem focalizar o homem que as ordenou; insurgem-se, numa palavra, contra os atos dos magistrados, mas jamais contra os magistrados. ${ }^{17}$

Eis dentro de que esfera se deve desenvolver a dialética do advogado com o juiz, em regime de cortesia, de lealdade, de respeito e sobretudo de dignidade humana. O êrro é dos homens. Erram os juízes; mas igualmente erram os advogados. Nem são poucas as vêzes em que êstes, pedindo reconsideração de despachos e até de decisões recorríveis, diante de sustentações justificadas, se desconvencem do que antes tinham como certeza. Apregôe cada um seu ponto de vista, forte mercê de sua convicção; mas não se desvista da sensibilidade necessária para o ato de contrição diante ao menos de sua própria consciência.

Animados advogado e juiz dêsse ânimo, que é o dos eleitos, não haverá debate, com espírito de cordialidade, que não seja profícuo, a despeito de que a palavra do advogado seja a do argumento e a do juiz a de decisão.

14. Nem sempre ao juiz apraz o discurso do advogado: é de sua preferência formular seu juízo em solilóquio. Arguto, num lance apreende a questão, mercê do hábito de perscrutá-la. Jurista, conhecedor da lei, é capaz de deslindar, por si mesmo, a relação processual. Efetivamente o é. Mas a lide não é abstrata. É concreta. Tem conteúdo complexo não poucas vêzes, de onde a exigência de maior acuidade para compreendê-la nas particularidades e no conjunto. E se lhe depara, predominantemen-

(17) Fernand Payen, Le Barreau (L'Art et la Fonction), Paris, 1934, Editions Bernard Grasset, pág. 202. 
te, uma pretenção, que deve ser ouvida, pela palavra do advogado do que a suscita ou do que a contesta. Solícito e paciente deve ser para a escutar e entender a fim de a acolher ou de a repelir.

Lei se promulgou determinando que, no julgamento perante os tribunais de recursos, feita a exposição dos fatos e proferido o voto do relator, sucessivamente se ouvissem os advogados do recorrente e do recorrido para a sustentação de suas conclusões, continuando o relator com a palavra para manter ou modificar o voto anteriormente expresso.

A inovação legislativa era salutar; e benéfica. Ensejava, expostos os fatos pelo relator, melhor esclarecê-los. Emitido seu voto, discuti-lo em seus fundamentos e conclusões, assim para combatê-lo, como para reforçá-lo, pelas vozes das duas partes litigantes, era o objetivo da lei, sobretudo para bem se focalizar o problema diante dos demais julgadores votantes de outiva e sem conhecimento direto do processo.

Não se sentiram bem os magistrados. Rebelaram-se contra a inovação. Mais, ainda, fulminaram-na, sob a alegação de sua inconstitucionalidade, que não era, nem é manifesta, com o só propósito de arredar os advogados da tribuna em momento em que poderiam perturbar a tranquilidade de seus monólogos.

15. Tem que ser dinâmica a dialética do advogado com o juiz. Se Hegel viu na guerra a dialética em ação, em verdade diz a sabedoria popular que da discussão nasce a luz, que ilumina e revela a verdade. O contacto do advogado com o juiz deve ser mais íntimo, sem quebra da verticalidade que os separa no plano judiciário, para que um e outro exercitem seu ofício com sobranceria. A majestade da justiça reside tôda inteira em cada sentença proferida pelo juiz em nome do povo soberano. 0 conceito é de Anatole France. 
Mas o autor de Crainquibille era diabólico. A justiça é social, acrescentou. Sòmente maus espíritos podem querê-la humana e sensível: ela se administra segundo regras fixas e não com os estremecimentos da carne e as claridades da inteligência. Não há sobretudo como lhe pedir que seja justa: ela não tem necessidade disso, pois que ela é justiça; e a idéia de justiça justa não pode germinar senão no cérebro dum anarquista.

O juiz Magnaud, observou por último, proferia sentencas cheias de equidade; mas eram cassadas, e isso era justiça. 